\title{
Preparation of $\mathrm{LiMn}_{2} \mathrm{O}_{4}$ films by sputtering method Masaaki Isai, Koichi Nakamura, and Takayuki Hosokawa
}

\author{
Department of Electrical \& Electronics, Faculty of Engineering, Shizuoka University \\ Johoku 3-5-1, Nakaku, Hamamatsu, Shizuoka, Japan 432-8561 \\ Fax: 053-478-1105, e-mail: temisai@ipc.shizuoka.ac.jp
}

\begin{abstract}
Manganese oxides have been studied as a cathode material in the $\mathrm{Li}$ secondary batteries. Preparation of $\mathrm{LiMn}_{2} \mathrm{O}_{4}$ thin films were tried with a sputtering method. This material is superior to other materials in the cost performance as well as non-toxicity. The crystal properties were improved after an annealing process. The preparation procedure is introduced through this study.
\end{abstract}

Keyword Li secondary batteries, Manganese oxide films, Li-Mn-O defect-spinel-structure, Sputtering method, Rapid thermal annealing

\section{Introduction}

The lithium $(\mathrm{Li})$ secondary batteries have been used for cell phones, video cameras, etc. The revolution of energy sources for electric vehicles has been started by using fuel cells and $\mathrm{Li}$ secondary batteries. These devices require the specific energy density more than $100 \mathrm{Wh} / \mathrm{kg}$ and the power density $40 \mathrm{~W} / \mathrm{kg}$. [1]

Various materials have been used for the positive electrodes of Li secondary batteries.[1, 2] Recently, various manganese oxides have been investigated as a positive electrode material. Manganese is less-toxic and abundant material as compared with Cobalt. We have been focusing especially on the Li-Mn-O defect-spinel-structure (so called defect-spinel-structure). [3,4] If this structure is adopted as a positive electrode, the operating voltage and theoretical capacity are $3-4 \mathrm{~V}$ and $148-213 \mathrm{mAh} / \mathrm{kg}$, respectively. $[3,4]$

The defect-spinel-structure is defined by $\mathrm{Mn}_{3} \mathrm{O}_{4}, \mathrm{Li}_{4} \mathrm{Mn}_{5} \mathrm{O}_{12}$ and $\lambda-\mathrm{MnO}_{2}$ triangle in the $\mathrm{Li}-\mathrm{Mn}-\mathrm{O}$ phase diagram as shown in Fig. 1. [4] Our goal is to prepare films with this structure. These defect-spinels are considered to have high structural stability upon insertion and desorption of $\mathrm{Li}$ ions. The defect-spinelstructure described above could be obtained through the reaction between $\mathrm{Li}$ and $\lambda-\mathrm{MnO}_{2}$ or $\mathrm{Mn}_{3} \mathrm{O}_{4} \cdot[5,6,16-23]$

Figure 2 shows the manganese-spinel-structure of $\mathrm{LiMn}_{2} \mathrm{O}_{4}$. There are vacancies (16c) near the 8a sites. $\mathrm{Li}^{+}$ions can diffuse alternatively, for example, from $8 \mathrm{a}$ to $16 \mathrm{c}$ and then to $8 \mathrm{a}$. [7]

All of the materials for the positive electrodes have been prepared by a sintering method.[3-9] These powders have to be mixed with some binders and high electric conductivity materials like carbon black to apply the metal electrode. This process has complex procedures and induces thick films. This is less attractive in the point of energy density than the deposition process proposed in this paper. In order to solve these problems, various deposition methods have been introduced. [10-23] In our early studies, $\mathrm{Mn}_{3} \mathrm{O}_{4}$ films have been successfully prepared. [15-23] But, unfortunately, charge-discharge curves could not be measured. It seems that this is due to the deficiency of $\mathrm{Li}$ ions moving between positive and negative electrodes during charge and discharge process.

In this study, a magnetron sputtering method was introduced to prepare manganese oxide films involving $\mathrm{Li}$ atoms. The results are shown in this article.

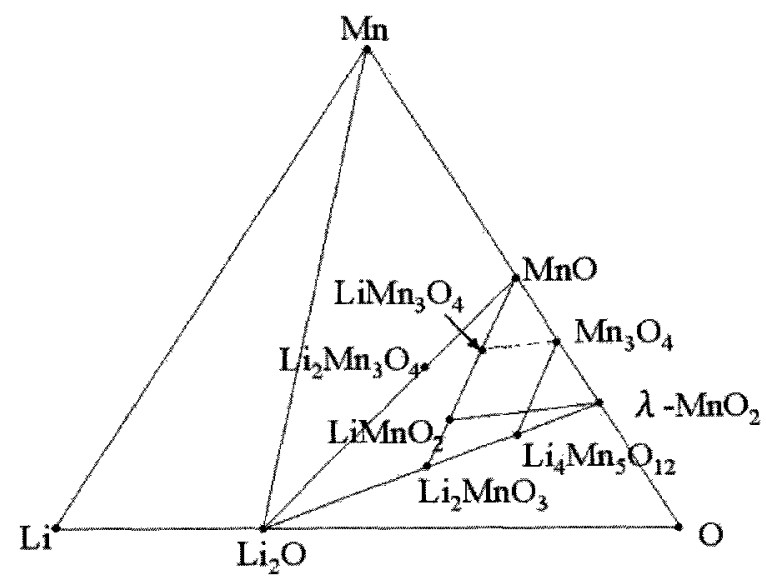

Fig. 1 Li-Mn-O phase diagram

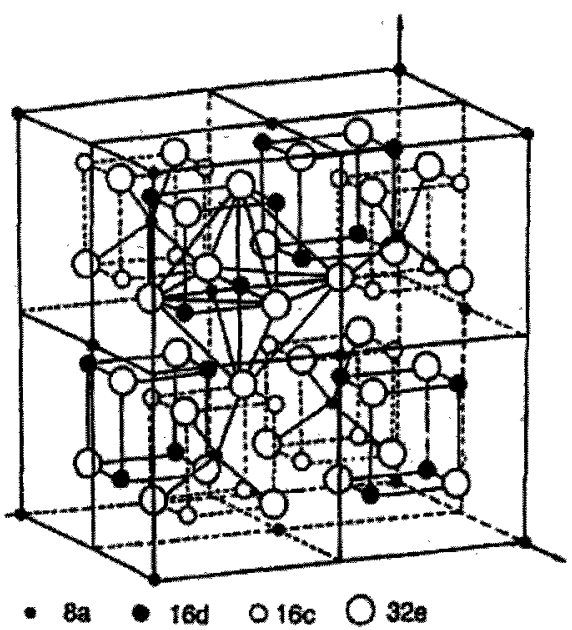

Fig. 2 Spinel structure of $\mathrm{LiMn}_{2} \mathrm{O}_{4}$

\section{Experiment}

$\mathrm{LiMn}_{2} \mathrm{O}_{4}$ films were prepared on $0.2 \mathrm{~mm}$-thick aluminum (Al) substrates by a magnetron sputtering method. The RF power was fixed at $100 \mathrm{~W}$ with varying the deposition time. The crystal structure of films was identified as $\mathrm{LiMn}_{2} \mathrm{O}_{4}$ by $\mathrm{X}$-ray diffraction (XRD) method.

The thickness of films was compared as a function of time. 
effect on the crystal structure was examined.

Figure 3 shows a magnetron sputtering apparatus. This apparatus has three targets in the vacuum chamber. So, it is easy to prepare multi-layered-devices without breaking vacuum.

In order to obtain crystallographic characteristics, X-ray diffraction (XRD) measurements were performed with a RIGAKU Rotaflex $12 \mathrm{~kW}$ with CN2173D6 goniometer. The film thickness was measured by an optical method (interference fringes) and gravimetric method.

Table 1 Deposition condition of $\mathrm{LiMm}_{2} \mathrm{O}_{4}$

\begin{tabular}{|c|c|}
\hline vacuum pressure [Pa] & $4-6$ \\
\hline RF power [W] & 100 \\
\hline Ar flow rate [sccm] & 4 \\
\hline parameter : deposition time [min] & $30,60,90$ \\
\hline target & $\mathrm{LiMn}_{2} \mathrm{O}_{4}$ \\
\hline
\end{tabular}

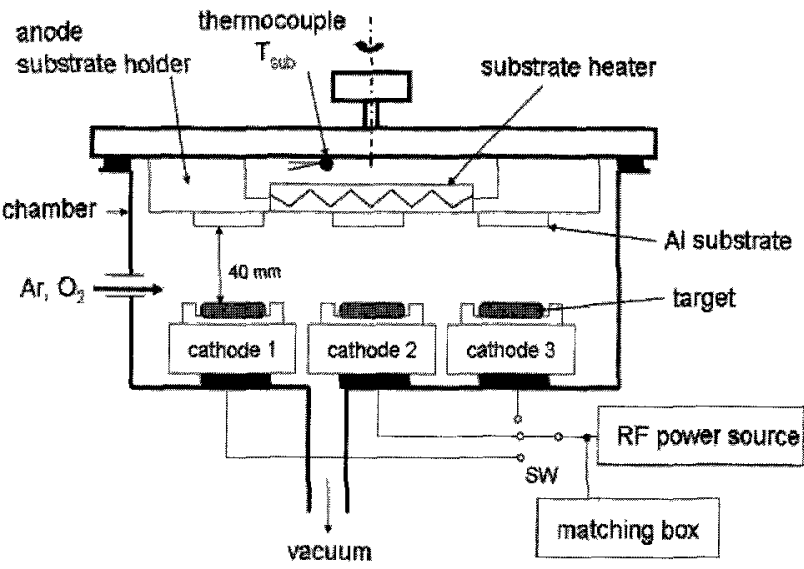

Fig. 3 Magnetron sputtering apparatus

\section{Results and Discussion}

Figure 4 shows XRD peaks of the deposited films as a function of deposition time. There are (111) and (222) peaks. They show that these films are constructed with $\mathrm{LiMn}_{2} \mathrm{O}_{4}$.

Figure 5 shows the dependence of film thickness on deposition time. From this result, it is found that the thickness is increased as increasing the deposition time. But, the thickness is gradually saturated after 60 -minute deposition time. It seemed due to the degradation of target material $\left(\mathrm{LiMn}_{2} \mathrm{O}_{4}\right)$. The films were sequentially deposited with varying deposition time from, 30,60 , and 90 minutes without breaking vacuum. The color of target surface was changed from black to brownish-colors after deposition process. It was noticed that the target surface has changed just after the first deposition run.

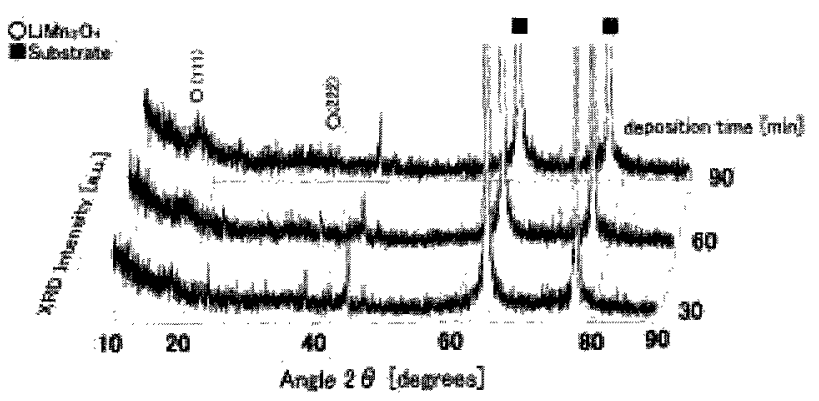

Fig. 4 XRD patterns of deposited films as a function of deposition time

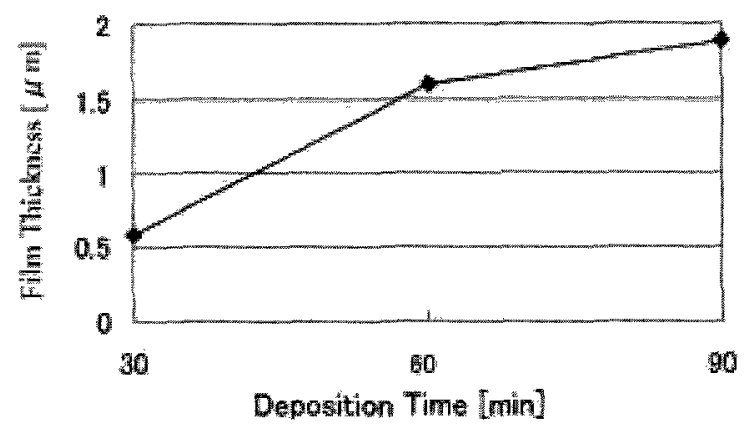

Fig. 5 Dependence of film thickness on deposition time

\section{Annealing Effect}

The annealing condition is shown in Table 2. The films for annealing process were deposited at $100 \mathrm{~W}$ for 60 minutes under $\mathrm{Ar}$ atmosphere. The annealing was controlled as a function of annealing time. The annealing time was varied as $1,2,5$ and 10 minutes. The annealing temperature was fixed at $400^{\circ} \mathrm{C}$. It was found that the crystallinity of films was improved after the annealing process.

Table 2 Annealing condition of $\mathrm{LiMn}_{2} \mathrm{O}_{4}$ films

\begin{tabular}{|c|c|}
\hline annealing temperature $\left[{ }^{\circ} \mathrm{C}\right]$ & 400 \\
\hline parameter : annealingtime [min] & $1,2,5,10$ \\
\hline
\end{tabular}

Figure 6 shows the XRD data of annealed films as varying the annealing time. A datum of un-annealed film is also shown for comparison. The strength of (111) peaks for all samples was increased after annealing process. It was recognized that the crystallinity of films was improved after annealing process.

Figure 7 shows the dependence of XRD intensity on the annealing time. The XRD intensity was gradually increased as increasing the annealing time. But, it saturates after 5 -minute annealing time. 


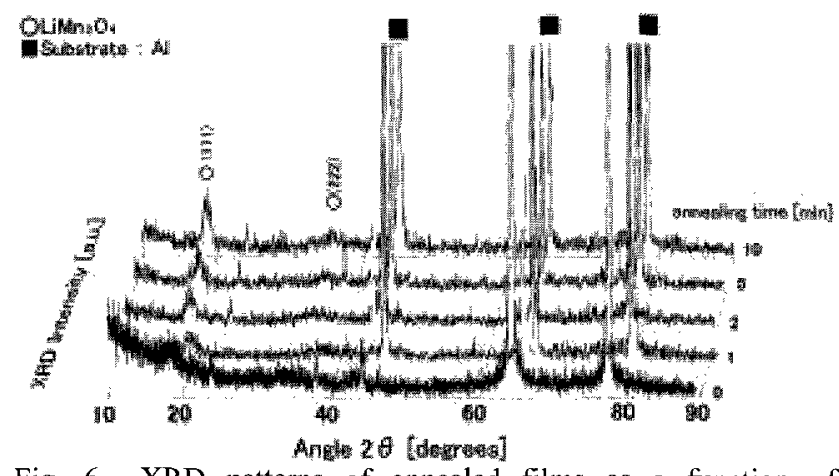

Fig. 6 XRD patterns of annealed films as a function of annealing time

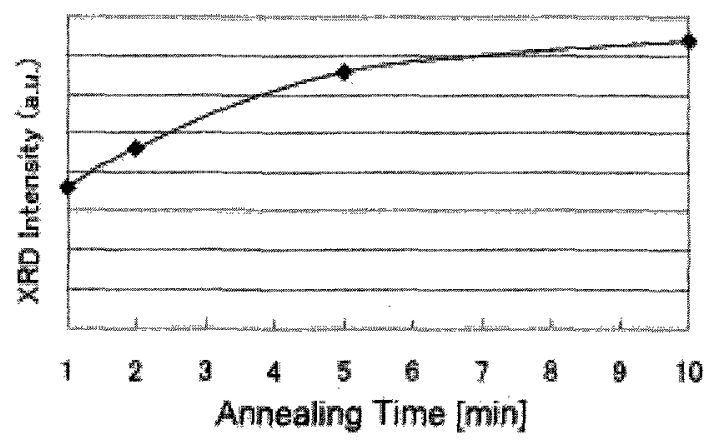

Fig. 7 Dependence of XRD intensity on the annealing time

It seemed that a degradation of films, for example, decreasing of film-thickness after re-evaporation of films and variation of composition were happened during annealing process. It is difficult to conclude whether the annealing time should be long or not. An optimum annealing condition will be studied after investigating the composition of annealed films.

In this study, $\mathrm{LiMn}_{2} \mathrm{O}_{4}$ was used as a target material. There are many other manganese oxide, for example $\mathrm{LiMnO}_{2}, \mathrm{Li}_{2} \mathrm{MnO}_{3}$, $\mathrm{LiMnO}_{4}$. A possibility of deviation from stoichiometry of target material after deposition runs has to be considered. There is some ideas which could overcome such a problem. The composition on the target surface could be maintained by using a reactive sputtering. The stoichiometry of films could be maintained by optimizing the flow rate of $\mathrm{Ar}$ to $\mathrm{O}_{2}$. The investigation of stoichiometry will be the subject of future study.

\section{Conclusion}

It was found that the $\mathrm{LiMn}_{2} \mathrm{O}_{4}$ films were successfully prepared by a magnetron sputtering method. The dependence of film thickness on deposition time was investigated. It was found that the thickness of films was increased by increasing the deposition time. But, the thickness is gradually saturated after 60-minute deposition time. The degradation of target material $\left(\mathrm{LiMn}_{2} \mathrm{O}_{4}\right)$ seems to be responsible for the crystallinity of films.

The dependence of annealing effect on annealing time was investigated. It was found that the crystallinity of films was improved after theannealing process. An optimum annealing condition has to be studied after investigating the composition of annealed films.

\section{Acknowledgement}

A part of this study has been supported by Shizuoka Research Institute and Hamamatsu Science and Technology Promotion Society. The support from the Grant-in-Aid for Scientific research (C) in the Ministry of Education, Culture, Sports, Science and Technology in Japan was also quite helpful. Several parts of vacuum apparatus have been made by K. Sahara, M. Iwasawa, A. Isogai, T. Matsuno, T. Okamoto and T. Kamio in the Manufacturing Center of Shizuoka University.

\section{Reference}

[1] Desilvestro and O. Haas, : "Metal oxide cathode materials for electrochemical energy storage: A Review"

J. Electrochem. Soc. 137, 5C ,1990

[2] R. Koksbang, J. Barker, H. Shi, and M. Y. Saidi, : "Cathode materials for lithium rocking chair batteries" Solid State Ionics 84, 1,1996

[3] M. M. Thackeray, A de Kock, M. H. Rossouw, D. Liles, R. Bittihn, and D. Hoge, : "Spinel electrodes for the Li-Mn-O system for rechargeable lithium batteries"

J. Electrochem. Soc. 139, 363,1992

[4] R. J. Gummow, A de Kock, and M. M. Thackeray, : "Improved capacity retention in rechargeable $4 \mathrm{~V}$ lithium/lithium manganese oxide (spinel) cells" Solid State Ionics, 69, 59,1994

[5] J. C. Hunter, : "Preparation of a new crystal form of manganese dioxides: $\lambda-\mathrm{MnO}_{2}$ " J. Solid State. Chem. 39, 142,1981

[6] M. M. Thackeray, P. J. Johnson, L A de Picciotto, P. G. Bruce, and J. B. Goodenough, : "Electrochemical extraction of lithium from $\mathrm{LiMn}_{2} \mathrm{O}_{4}$ "' Mat. Res. Bull. 19, 179,1984

[7] M. M. Thackeray, W. I. F. David, P. G. Bruce, and J. B. Goodenough, : " Lithium insertion into manganese spinels" Mater. Res. Bull. 18, 461,1983

[8] W. I .F. David, M.M. Thackeray, L. A. De Picciotto, and J. B. Goodenough,: "Structure refinement of the spinel-related phases $\mathrm{Li}_{2} \mathrm{Mn}_{4} \mathrm{O}_{4}$ and $\mathrm{Li}_{0.2} \mathrm{Mn}_{2} \mathrm{O}_{4} "$ J. Solid State Chem. 67, 316,1987

[9] Y. Xia and M. Yoshio, : "An investigation of lithium ion insertion into spinel structure Li-Mn-O compouds" J. Electrochem. Soc. 143, 825,1996

[10] Y. Bando, S. Horii, and T. Tanaka, : " Reactive condensation and magnetic properties of ion oxide films" Jpn. J. Appl. Phys. 17, 1037, 1978

[11] K. A. Striebel, C. Z. Deng, S. J. Wen, and E. J. Cairns, : "Electrochemical behavior of $\mathrm{LiMn}_{2} \mathrm{O}_{4}$ and $\mathrm{LiCoO}_{2}$ thin films produced with pulsed laser deposition" J. Electrochem. Soc. 143, 1821,1996

[12] F. K. Shokoohi, J. M. Tarascon, B. J. Wilkens, D. Guyomard, and C. C. Chang, : "Low temperature $\mathrm{LiMn}_{2} \mathrm{O}_{4}$ spinel films for secondary lithium batteries" J. Electrochem. Soc. 139, 1845,1992

[13] A. Rougier, K. A. Striebel, S. J. Wen, and E, J. Cairns, : "Cyclic voltammetry of pulsed laser deposited $\mathrm{Li}_{\mathrm{x}} \mathrm{Mn}_{2} \mathrm{O}_{4}$ thin films" J. Electrochem. Soc. 145, 2975,1998

[14] P. Liu, J. G. Zhang, J. A. Turner, C. E. Tracy, and D. K. Benson, : "Lithium-manganese-oxide thin-film cathodes prepared by plasma-enhanced chemical vapor deposition"

J. Electrochem. Soc. 146, 2001,1999

[15] M. Isai, K. Yamaguchi, H. Iyoda, H. Fujiyasu, and Y. Ito, : "Oxygen gettering effect during the reactive evaporation of manganese films"

J. Mater. Res. 14, 1653,1999 
[16] M. Isai, H. Ichikawa, T. Shimada, K. Morimoto, H. Fujiyasu, and Y. Ito, : "Priority of the Mn deposition rate in the reactive evaporation conditions" Jpn. J. Appl. Phys. 39,6676,2000

[17] M. Isai, H. Ichikawa, H. Takahashi, H. Fujiyasu, and Y. Ito, : "An idea of overcoming the oxidation of Mn metal in the crucible during the reactive evaporation process" Electrochemistry 68, 963,2000

[18] M. Isai, T. Shimada, T. Matsui, and H. Fujiyasu, : "A new technique keeping off the $\mathrm{Mn}$ evaporant from oxygen atmosphere during the reactive evaporation process" Jpn. J. Appl. Phys. 40,5069,2001

[19] M. Isai and H. Fujiyasu, : "Prevention against oxidation of Mn evaporant during reactive evaporation process" Jpn. J. Appl. Phys. 40,6552,2001

[20] M. Isai, Y. Nagashio, T. Tatei, and H. Fujiyasu, : "Stabilization of deposition rate of Mn oxide films by using SUS cell"

Trans. Mater. Res. Soc. Jpn. 30,1031,2005

[21] M. Isai : "Research on reactively evaporated Mn oxide films"

Trans. Mater. Res. Soc. Jpn. 31,1025,2006

[22] M. Isai : "Preparation of manganese oxide films for $\mathrm{Li}$ secondary batteries"

Trans. Mater. Res. Soc. Jpn. 31,1037,2006

[23] M. Isai, Y. Chonan, Y. Tojo: "Preparation of lithium manganese oxide films for Li secondary batteries"

Trans. Mater. Res. Soc. Jpn. 32,1203,2007

(Recieved December 8, 2007 ; Accepted June 17, 2008) 